\title{
Cancer type-specific modulation of mitochondrial haplogroups in breast, colorectal and thyroid cancer
}

Hezhi Fang ${ }^{1}$, Lijun Shen ${ }^{1}$, Tao Chen ${ }^{1}$, Jing He${ }^{1}$, Zhinan Ding ${ }^{1}$, Jia Wei ${ }^{1}$, Jianchun ${ }^{1}{ }^{1}$, Guorong Chen ${ }^{2}$, Jianxin Lu*, Yidong Bai ${ }^{1,3^{*}}$

\begin{abstract}
Background: Mitochondrial DNA (mtDNA) haplogroups and single nucleotide polymorphisms (mtSNP) have been shown to play a role in various human conditions including aging and some neurodegenerative diseases, metabolic diseases and cancer.

Methods: To investigate whether mtDNA haplogroups contribute to the occurrence of cancer in a specific Chinese population, we have carried out a comprehensive case-control study of mtDNA from large cohorts of patients with three common cancer types, namely, colorectal cancer $(n=108)$, thyroid cancer $(n=100)$ and breast cancer $(n=$ 104), in Wenzhou, a southern Chinese city in the Zhejiang Province.

Results: We found that patients with mtDNA haplogroup $M$ exhibited an increased risk of breast cancer occurrence $[\mathrm{OR}=1.77 ; 95 \% \mathrm{Cl}(1.03-3.07) ; \mathrm{P}=0.040]$, and that this risk was even more pronounced in a subhaplogroup of $\mathrm{M}, \mathrm{D} 5[\mathrm{OR}=3.11 ; 95 \% \mathrm{Cl}(1.07-9.06) ; \mathrm{p}=0.030]$. In spite of this, in patients with breast cancer, haplogroup $M$ was decreased in the metastatic group. On the other hand, our results also showed that haplogroup D4a was associated with an increased risk of thyroid cancer [OR $=3.00 ; 95 \% \mathrm{Cl}(1.09-8.29) ; \mathrm{p}=0.028]$. However, no significant correlation has been detected between any mtDNA haplogroups and colorectal cancer occurrence.
\end{abstract}

Conclusion: Our investigation indicates that mitochondrial haplogroups could have a tissue-specific, populationspecific and stage-specific role in modulating cancer development.

\section{Background}

Mitochondria, known as the cellular power plants, also regulate cell death and cell proliferation[1]. Mitochondria are under dual genome control. Human mtDNA encodes 13 essential subunits of the oxidative phosphorylation (OXPHOS) system as well as 2 rRNAs and 22 tRNAs used in mitochondrial translation. Alterations in mtDNA including both mutations and polymorphisms have the potential of changing the capacity of mitochondrial function. In particular, changes in oxidative phosphorylation resulting from mitochondrial dysfunction have long been hypothesized to be involved in

\footnotetext{
*Correspondence: jxlu313@163.com; baiy@uthscsa.edu

'Zhejiang Provincial Key Laboratory of Medical Genetics, Wenzhou Medical College, Wenzhou 325035, China

Full list of author information is available at the end of the article
}

tumorigenesis. To explain the fact that cancer cells were high in fermentation and low in respiration, Warburg proposed that cancer originated from a non-neoplastic cell which adopted anaerobic metabolism as a means of survival after injury to its respiratory system[2], which led to the notion that tumors were initiated by persistent damage to the mitochondria[3,4]. Supporting such idea, changes in the number, shape, and function of mitochondria have been reported in various cancers [5]. Interestingly, abnormal mtDNA was observed in leukemic myeloid cells using an electron microscope[6,7] long before DNA sequencing technology was available. Subsequently, mutations in both the non-coding and coding regions of the mtDNA have been identified in various types of cancer [8-10].
C Biomed Central

() 2010 Fang et al; licensee BioMed Central Ltd. This is an Open Access article distributed under the terms of the Creative Commons Attribution License (http://creativecommons.org/licenses/by/2.0), which permits unrestricted use, distribution, and reproduction in any medium, provided the original work is properly cited. 
mtDNA is predominantly maternally inherited, and largely lacks recombination[11]. A human mtDNA haplogroup is defined by unique sets of mtDNA polymorphisms, reflecting mutations accumulated by a discrete maternal lineage[12]. The haplogroups are associated with region-specific mtDNA sequence variation as a result of genetic drift and/or adaptive selection for an environment-favored mitochondrial function[13,14]. Difference in redox signaling as a consequence of haplogroup-associated oxidative phosphorylation capacity has been suggested as the molecular mechanism involved in the haplogroups-associated phenotypes $[15,16]$. The haplogroup association studies have been used to investigate the effect of mtDNA variants on various complex conditions such as aging[17,18], metabolic diseases[19,20], neurodegenerative diseases [21,22], infectious diseases $[23,24]$ and cancer[3,8,9]. In particular, haplogroups D4a, D5 and D4b2b were reported to be increased in centenarians in Japanese [25,26], while D4 was found to be enriched in female and N9 and M9 decreased in a Chinese population in Rugao area[17]. mtSNP at 10398, which is a major diagnostic site for macro-haplogroups $\mathrm{M}$ and $\mathrm{N}$ in Chinese population $[27,28]$, has been implicated in longevity[29], Parkinson's disease[30], and breast cancer in various populations in some seemingly conflicting reports[31-34]. Interestingly, while reported as enriched in group exhibits longevity, D4a and D5a were observed to increase susceptibility in a Chinese population to esophageal carcinoma[35].

To assess the possible contribution of mtDNA haplogroup-specific polymorphisms to the prevalence of cancer in a southern Chinese population, we performed a case-control study of patients with three of the local most common types of cancer, breast cancer, thyroid cancer and colorectal cancer in Wenzhou, Zhejiang Province of China.

\section{Methods}

\section{Subjects}

The number and age information (in years) for the cancer patients used in this study: 108 colorectal cancer patients (mean \pm SD $62.98 \pm 12.63$, median $=64$, range 30-88), 104 breast cancer patients (mean \pm SD $51.6 \pm$ 10.29 , median $=51$, range $27-79$ ) and 100 thyroid cancer patients (mean \pm SD $45.98 \pm 12.59$, median $=46$, range 20-84). The patients were recruited when they were admitted for surgery at the First Affiliated Hospital of Wenzhou Medical College from May, 2007 to November, 2008. Histological confirmations of each cancer type were carried out immediately following each surgery. Three sets of age, gender and geographically matched control subjects who had a cancer-free history, and had no other known diseases which could be associated with mitochondrial defects were also recruited at the Physical Examination Center of the same hospital from October, 2008 to December, 2008. The numbers and ages (in years) of controls for each study are as follows: $\mathrm{n}=124$ (mean \pm SD $60.15 \pm 9.3$, median $=60$, range 37-84) for the colorectal cancer study, $\mathrm{n}=114$ $($ mean \pm SD 53.44 \pm 11.66 , median $=52$, range 27-84) for the breast cancer study, and $n=138$ (mean \pm SD $47.96 \pm 6.64$, median $=49$, range $27-62$ ) for the thyroid cancer study. Informed consents were obtained from all patients and controls according to the regulations set forth by the ethical committee of Wenzhou Medical College.

\section{mtDNA sequencing}

About $2 \mathrm{ml}$ venous blood was collected from each sample before surgery and any drug treatment. Total DNA was extracted using a standard phenol-chloroform method as described previously[36]. The sequences of two pairs of primers designed to amplify the mtDNA Dloop and ND3+tRNA ${ }^{\text {arg }}+\mathrm{ND} 4 \mathrm{~L}$ region were as follows, L15792F: TCATTGGACAAGTAGCATCC, H794R: AGGCTAAGCGTTTTGAGCTG and L9967F: TCTCCATCTATTGATGAGGGTCT, H10858R: AATTAGGCTGTGGGTGGTTG[37]. PCR was performed on a Thermal Cycler 170-9703 PCR machine (BIORAD, USA). The PCR conditions were as follows: predenaturation at $95^{\circ} \mathrm{C}$ for $5 \mathrm{~min}$, then 35 cycles of $\left[94^{\circ} \mathrm{C}\right.$ for $30 \mathrm{~s}, 57^{\circ} \mathrm{C}$ for $35 \mathrm{~s}, 72^{\circ} \mathrm{C}$ for $\left.1 \mathrm{~min}\right]$, and a final extention at $72^{\circ} \mathrm{C}$ for $4 \mathrm{~min}$. The PCR products were purified using the Agarose Gel DNA Fragment Recovery Kit Ver.2.0 (TaKaRa, Japan) and subsequently sequenced on an ABI Prism 3730 sequence analyzer.

\section{mtDNA haplogroup and mtSNPs analysis}

To assign a mtDNA haplogroup to each sample, all sequences were compared with the revised Cambridge Reference Sequence (rCRS)[38] and aligned using the CodonCode Aligner 3.0.1 (CodonCode Corporation, USA)[37] software program. Based on the most recent refined East Asian mitochondrial haplogroup tree $[27,28,39]$, the initial assignment was performed with the sequencing information from the D-loop, ND3 and ND4L regions. When necessary, additional information was obtained by restriction fragment length polymorphism (RFLP) analysis at sites: 663 (HaeIII), 3394 (HaeIII), 4833 (HhaI), 5178 (AluI) and 9824 (HinfI). With some samples, the $9 \mathrm{bp}$ deletion at the COII-tRNA ${ }^{\text {lys }}$ junction was also detected to further identification.

\section{Statistical analysis}

All statistical analyses were performed using SPSS software (version 13.0) (SPSS Inc., Chicago, IL, USA). The Pearson chi-square test was used to analyze the relationship between the prevalence of haplogroups and 
different cancer features. Binary logistic regression analysis was also carried out to determine the contributions of haplogroup and other risk factors to cancer features.

\section{Results}

\section{Macro-haplogroups $\mathrm{M}$ and $\mathrm{N}$ on breast cancer}

Macro-haplogroups $\mathrm{M}$ and $\mathrm{N}$ are major descendents of L3, a superhaplogroup and an "African Eve" which shapes all various sub-lineages out of Africa[12,40]. These specific haplogroups could be identified by the polymorphisms at positions 10400 and 10398 in the Chinese Han population, where $\mathrm{M}$ is defined by $\mathrm{T}$ at 10400 and likely exhibits G at 10398 whereas N has A at 10398 as in the Cambridge Standard sequence[28] (Figure.1). It was reported that haplogroup $\mathrm{N}$ was associated with an increased risk of breast cancer in the Indian population[33]. Interestingly, 10398A in AfricanAmerican[31] and 10398G in European-American[34] populations were both reported to correlate with increased breast cancer risks.

In a case-control study (CCS) conducted with breast cancer patients in a southern Chinese population, we tested the correlation between macro-haplogroups $\mathrm{M}$ and $\mathrm{N}$ and breast cancer incidence. We found that haplogroup $\mathrm{M}$ posed a significant risk for breast cancer $(\mathrm{OR}=1.77$; $95 \%$ CI 1.03-3.07; $\mathrm{P}=0.040$ ), whereas haplogroup $\mathrm{N}$ was associated with a decreased incidence $(\mathrm{OR}=0.56 ; 95 \% \mathrm{CI}$ 0.33-0.98; $\mathrm{P}=0.040$ ) (Table 1). Following age-adjustment of the data in a binary logistic regression analysis, the results became even more significant. Haplogroup M had a higher occurrence in breast cancer patients $(\mathrm{OR}=1.84$; $95 \%$ CI 1.07-3.20; $\mathrm{P}=0.029$ ), whereas haplogroup $\mathrm{N}$ was decreased in frequency $(\mathrm{OR}=0.54 ; 95 \% \mathrm{CI} 0.31-0.94 ; \mathrm{P}=$ 0.029). We then examined the mtSNP at position 10398, and found that 10398G was correlated with an increased incidence of breast cancer $(\mathrm{OR}=1.77$; $95 \% \mathrm{CI} 1.00-3.14$; P $=0.050)$, and 10398A showed a protection effect $(\mathrm{OR}=$ 0.56 ; 95\% CI 0.32-1.00; $\mathrm{P}=0.050$ ) (Table 1). A stronger influence was revealed after a binary logistic regression analysis for the age-adjustment for both 10398G (OR = 1.98 ; $95 \% \mathrm{CI} 1.11-3.53, \mathrm{P}=0.021)$ and $10398 \mathrm{~A}(\mathrm{OR}=0.51$, $95 \%$ CI $0.28-0.90, \mathrm{P}=0.021$ ).

We also analyzed some clinical characteristics and other risk factors for breast cancer in the breast cancer patients divided among macro-haplogroups $\mathrm{M}$ and $\mathrm{N}$. As shown in Table 2, age is not a contributing factor ( $\mathrm{P}$
Table 2 Stratification of clinical characteristics in breast cancer cases with haplogroup $\mathbf{M}$ and $\mathbf{N}$

\begin{tabular}{|c|c|c|c|c|}
\hline \multirow[t]{2}{*}{ Variable } & \multirow[t]{2}{*}{ Value } & \multicolumn{2}{|c|}{ Haplogroups } & \multirow[t]{2}{*}{$P$ value } \\
\hline & & $M(n)$ & $N(n)$ & \\
\hline Cancer metastasis & & & & $0.044^{*}$ \\
\hline yes & 34 & 18 & 16 & \\
\hline No & 70 & 51 & 19 & \\
\hline Progesterone receptor (PR) & & & & 0.818 \\
\hline PR positive & 64 & 43 & 21 & \\
\hline PR negative & 40 & 26 & 14 & \\
\hline Estrogen receptor (ER) & & & & 0.932 \\
\hline ER positive & 63 & 42 & 21 & \\
\hline ER negative & 41 & 27 & 14 & \\
\hline Age & & & & 0.838 \\
\hline$\leq 50$ & 49 & 33 & 16 & \\
\hline$>50$ & 55 & 36 & 19 & \\
\hline BMI & & & & 0.832 \\
\hline $18-25$ & 55 & 37 & 18 & \\
\hline$>25$ or $<18$ & 49 & 32 & 17 & \\
\hline
\end{tabular}

$P$ values were estimated by "chi-square test"; (*) indicated statistical significant $(\mathrm{P}<0.05)$. BMI, body mass index; BMI ranging18-25 is considered as normal.

$=0.838)$ to the differences we observed in breast cancer patients with macro-haplogroups $M$ and N. Similarly, we did not detect a significant difference in Body Mass Index (BMI) between these patients. Further investigation of the expression of progesterone receptor (PR) and estrogen receptor (ER) failed to reveal any difference between the $\mathrm{M}$ and $\mathrm{N}$ haplogroups. However, surprisingly we found an enriched presentation of the $\mathrm{N}$ haplogroup in patients with metastatic breast cancer $(\mathrm{P}=$ 0.044). After adjusting with co-variants like age, BMI, PR and ER expression, $\mathrm{N}$ still exhibited a significantly higher occurrence in the metastatic group $(\mathrm{OR}=0.39$; 95\%CI 0.17-0.94; $\mathrm{P}=0.036$ ).

\section{Haplogroup analysis in breast cancer, colorectal cancer and thyroid cancer patients}

We furthered our investigation by performing a more detailed sub-haplogroup analysis. As described in the Materials and Methods section, based on the mtSNPs shown in Figure 1, we were able to assign 104 breast cancer patients and 114 controls to 12 sub-haplogroups. As shown in Table 3, we found haplogroup D5, a sub-haplogroup of D under M (Figure. 1), displayed a significantly higher frequency in breast cancer

Table 1 Effect of macro haplogroup $M$ and $N$ on breast cancer occurrence

\begin{tabular}{|c|c|c|c|c|c|c|c|c|c|}
\hline \multirow[t]{2}{*}{ Sample } & \multirow[t]{2}{*}{ Value } & \multicolumn{2}{|c|}{ Haplogroups } & \multirow[t]{2}{*}{$P$ value } & \multirow[t]{2}{*}{ OR $(95 \% \mathrm{Cl})$} & \multicolumn{2}{|c|}{10398} & \multirow[t]{2}{*}{$P$ value } & \multirow[t]{2}{*}{ OR $(95 \% \mathrm{Cl})$} \\
\hline & & $M(n)$ & $N(n)$ & & & G & A & & \\
\hline Cases & 104 & 69 & 35 & $0.040^{*}$ & $1.77(1.03-3.07)$ & 76 & 28 & $0.050^{*}$ & $1.77(1.00-3.14)$ \\
\hline Controls & 114 & 60 & 54 & & & 69 & 45 & & \\
\hline
\end{tabular}

$P$ values were estimated by "chi-square test"; $(*)$ indicated statistical significant $(\mathrm{P}<0.05)$. OR indicates odds ratio; $95 \% \mathrm{Cl}$, $95 \%$ confidence interval. 


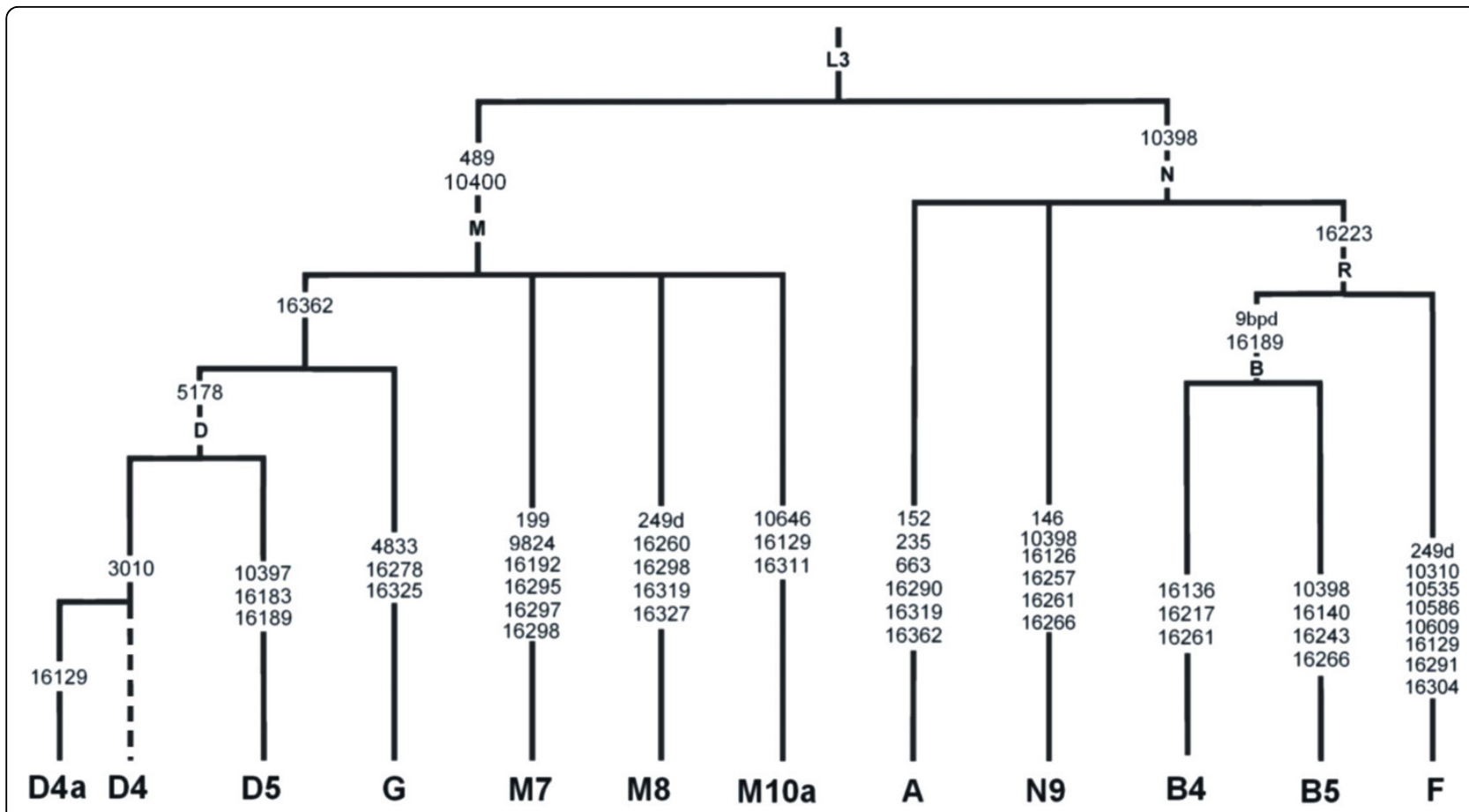

Figure 1 Classification of $12 \mathrm{mtDNA}$ haplogroups in subjects of three case-control studies. The defining sites[38] (as compared with the revised (RS) utilized in this study are listed in the branches. " $\mathrm{d}$ " indicates a deletion; "9 bpd" indicates a 9 bp deletion in the intergenic mtDNA region between nucleotides 8195-8316[53].

patients compared with control subjects $(\mathrm{OR}=3.11$; 95\%CI 1.07-9.06; $\mathrm{P}=0.030)$. This significant correlation remained after age-adjustment of the data in binary logistic regression analysis $(\mathrm{OR}=3.13 ; 95 \% \mathrm{CI}$ : 1.07-9.13; $\mathrm{P}=0.037$.

To determine if the coincidence of a specific mtDNA haplogroup with breast cancer indicates a general role in tumorigenesis in the southern Chinese population, we extended our studies to two other common cancer types in the Wenzhou area, colorectal cancer and thyroid cancer. Similar case-control studies were conducted on colorectal cancer and thyroid cancer patients. As shown in Table 3, unlike what we observed for breast cancer, there was no correlation between haplogroups $\mathrm{M}, \mathrm{N}$ or D5 and occurrences of these cancers. However, our results revealed that haplogroup D4a, a sub-haplogroup of D4, which shares the same ancestry of D and $M$ with D5 (Figure. 1), had a significantly higher frequency in thyroid cancer patients relative to control subjects (OR $=3.00 ; 95 \% \mathrm{CI} 1.087-8.29 ; \mathrm{P}=0.028$ ). After adjusting the data for age and gender in binary logistic regression analysis, the observed difference between cases and controls remained significant $(\mathrm{OR}=3.18$; 95\%CI 1.11-9.11; $\mathrm{P}=0.031$ ). Nevertheless, no significant correlation has been detected between any mtDNA haplogroups and colorectal cancer occurrence (Table 3).
mtSNP and combinations of mtSNPs in breast cancer, colorectal cancer and thyroid cancer patients

To determine the incidence of individual mtSNPs within haplogroups D4a and D5 in breast or thyroid cancer patient samples, we performed a stepwise investigation of the formation of the D5 and D4a sub-haplogroups and examined their potential correlation with cancer occurrences. As shown in Table 4, the combination of 10400T and 489C, which mostly determined macro-haplogroup $M$ in the Chinese Han population, was associated with an increased breast cancer incidence. An additional $16362 \mathrm{C}$, which mostly further defined the D plus $G$ haplogroups, somehow negated such a correlation, whereas 10397G, which helped to determine D5, restored the observed association with an increased risk of breast cancer. Individually, only 10398G (people with $10397 \mathrm{G}$ all belong to this group) exhibited an increased frequency in breast cancer patients relative to control subjects. For thyroid cancer, the combination of $16362 \mathrm{C}$ and $16129 \mathrm{~A}$, both in the highly variable area of the Dloop region, exhibited a significant correlation with cancer incidence.

In addition, all of the mtSNPs in the D-loop region, which were not utilized to determine the haplogroups and identified with a frequency of more than $5 \%$ in this study, were also analyzed. As shown in Table 5, none of 
Table 3 Effect of haplogroups on breast, colorectal and thyroid cancer occurrences

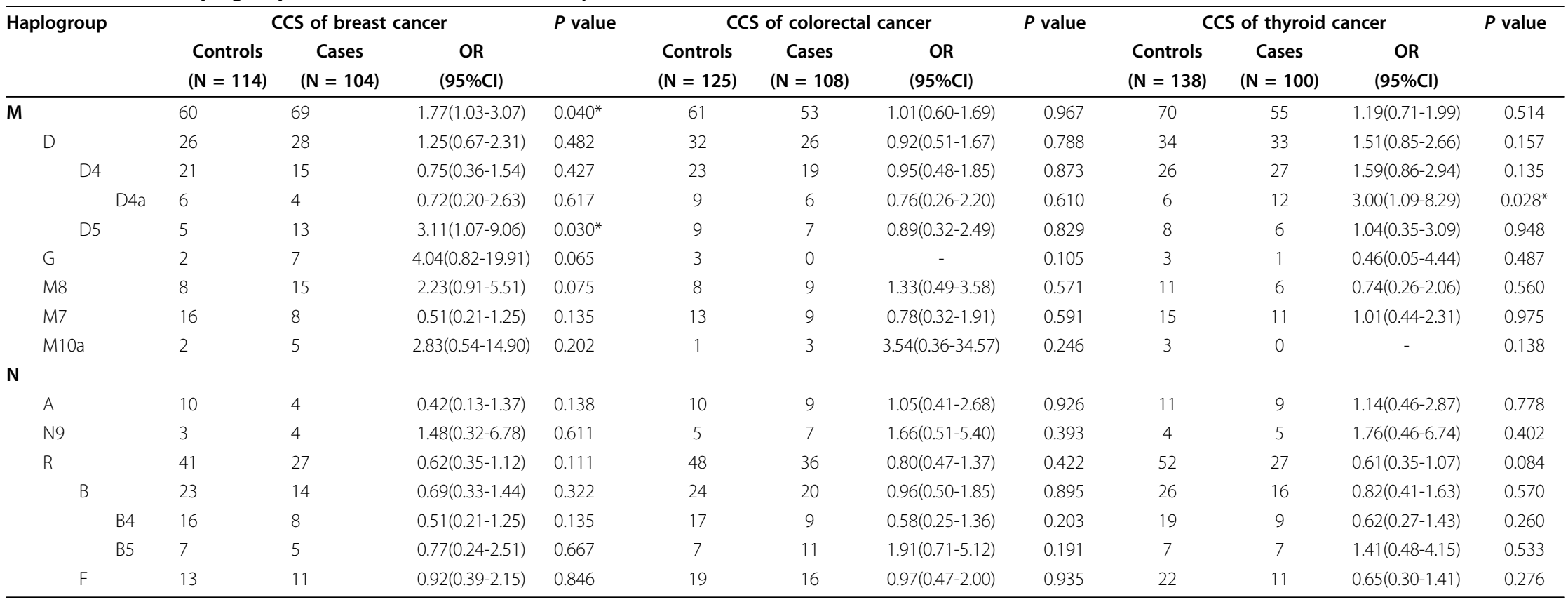

$P$ values were estimated by "chi-square test"; (*) indicated statistical significant $(P<0.05)$. OR indicates odds ratio; $95 \% \mathrm{Cl}, 95 \%$ confidence interval. 
Table 4 Effect of D4a and D5 determining mtSNPs on breast cancer and thyroid cancer

\begin{tabular}{|c|c|c|c|c|c|c|c|c|}
\hline \multirow[t]{2}{*}{ mtSNP } & \multicolumn{3}{|c|}{ CCS of breast cancer } & \multirow[t]{2}{*}{$P$ value } & \multicolumn{3}{|c|}{ CCS of thyroid cancer } & \multirow[t]{2}{*}{$P$ value } \\
\hline & $\begin{array}{l}\text { Controls } \\
(\mathrm{N}=114)\end{array}$ & $\begin{array}{c}\text { Cases } \\
(\mathrm{N}=104)\end{array}$ & $\begin{array}{c}\text { OR } \\
(95 \% \mathrm{Cl})\end{array}$ & & $\begin{array}{l}\text { Controls } \\
(\mathrm{N}=138)\end{array}$ & $\begin{array}{c}\text { Cases } \\
(\mathrm{N}=100)\end{array}$ & $\begin{array}{c}\text { OR } \\
(95 \% \mathrm{Cl})\end{array}$ & \\
\hline C10400T (T489C) & 60 & 69 & $1.77(1.03-3.07)$ & $0.040^{*}$ & 70 & 55 & 1.19(0.71-1.99) & 0.514 \\
\hline $\mathrm{T} 16362 \mathrm{C}+\mathrm{C} 10400 \mathrm{~T}(\mathrm{~T} 489 \mathrm{C})$ & 30 & 35 & $1.42(0.79-2.54)$ & 0.237 & 38 & 36 & $1.48(0.85-2.57)$ & 0.164 \\
\hline A10397G+T16362C+C10400T(T489C) & 4 & 13 & $3.93(1.24-12.46)$ & $0.013^{*}$ & 6 & 6 & $1.40(0.44-4.49)$ & 0.565 \\
\hline $\mathrm{G} 16129 \mathrm{~A}+\mathrm{T} 16362 \mathrm{C}+\mathrm{C} 10400 \mathrm{~T}(\mathrm{~T} 489 \mathrm{C})$ & 6 & 4 & $0.72(0.20-2.63)$ & 0.617 & 6 & 12 & $3.00(1.09-8.29)$ & $0.028^{*}$ \\
\hline A10397G+C10400T(T489C) & 5 & 13 & $3.11(1.07-9.06)$ & $0.030^{*}$ & 8 & 6 & 1.04(0.35-3.09) & 0.948 \\
\hline A10397G & 5 & 13 & $3.11(1.07-9.06)$ & $0.030^{*}$ & 8 & 6 & 1.04(0.35-3.09) & 0.948 \\
\hline A10398G & 69 & 76 & $1.77(1.00-3.14)$ & $0.050^{*}$ & 74 & 66 & $1.08(0.64-1.83)$ & 0.766 \\
\hline T16362C & 37 & 37 & $1.15(0.66-2.01)$ & 0.627 & 50 & 43 & $1.33(0.78-2.25)$ & 0.291 \\
\hline G16129A & 27 & 31 & $1.53(0.84-2.78)$ & 0.165 & 28 & 28 & $1.53(0.84-2.79)$ & 0.166 \\
\hline
\end{tabular}

$P$ values were estimated by "chi-square test"; $\left(^{*}\right)$ indicated statistical significant $(\mathrm{P}<0.05)$. OR indicates odds ratio; $95 \% \mathrm{Cl}, 95 \%$ confidence interval.

them displayed significant association with the occurrence of either of the cancer types.

\section{Discussion}

In this study, a total of 312 cancer patients (104 with breast cancer, 108 with colorectal cancer and 100 with thyroid cancer) and their matched control subjects were analyzed for the mitochondrial haplogroups and some related mtSNPs. In the Wenzhou area, breast cancer ranks number one in cancer occurrence among females, as in the other regions of the world. Thyroid cancer ranks number one in the age group of 15-34, and colon cancer tops liver, lung and stomach cancers, in cancer patients under 15 years old, both indicating a genetic predisposition[41]. An age and regional matched study increased our chances of discovering a contribution from mtDNA.

The first finding of our study is that macro-haplogroup $M$ has an increased frequency in breast cancer patients relative to controls, and intriguingly, breast cancer patients in macro-haplogroup $\mathrm{N}$ are more likely to exhibit metastatic tumors. Previously, a similar CCS with 124 sporadic breast cancer patients and 273 controls, together with analysis of 2334 individuals belonging to 18 regions in India, led to the proposition that mtSNP 10398A imparted haplogroup $\mathrm{N}$ with an increased risk for breast cancer[33].

A10398G is probably one of the best studied mtSNPs, in particular with respect to its potential effect on tumorigenesis. Noticeably, A10398G changes a threonine residue (A allele) to an alanine ( $G$ allele) at the C-terminus of the ND3 subunit of respiratory complex I. Using the cybrids system, it was reported that the closely linked 8701A/10398A mtSNPs were associated with a lowered mitochondrial matrix $\mathrm{pH}$, and at the same time an increased basal level of mitochondrial calcium and cytosolic calcium response to histamine[42].
A series of epidemiological investigations of neurodegenerative diseases like Parkinson's disease[30], Alzheimer's disease[43], and amyotropic lateral sclerosis (ALS) [44] suggested that the 10398A allele is associated with the degenerative phenotype.

In a large population-based CCS with 654 cases and 605 controls, African-American women with the 10398A allele were shown to have a significant risk of invasive breast cancer, but such a correlation was not observed in white women[31]. In a separate CCS with 156 unrelated European-American women with familial breast cancer and 260 controls, $10398 \mathrm{G}$ was associated with an increased risk of breast cancer[34]. An independent investigation carried out with a Polish breast cancer population also suggested $10398 \mathrm{G}$ as an inherited predisposition factor for the development of breast cancer[45]. However, other studies of either African-American females[46] or Spain and Canary Islands women[47] failed to confirm a role for mtSNP at 10398 in breast cancer development. Nevertheless, 10398G was found as a risk factor in oral cancer among Indian smokers[48].

To reconcile these seemingly conflicting results, based on our own data, we proposed that the combination of certain mtDNA haplogroups or mtSNPs (in this case, $10398 \mathrm{~A}$ or $\mathrm{G}$ ) with other nuclear encoded factors (some potentially tissue-specific), could play a role in tumorigenesis. The net result could be either alteration of calcium or redox signaling. It is also important to note that the enhanced generation of reactive oxygen species (ROS), which has been suggested by several investigators as a likely underlying mechanism by which mitochondrial haplogroups and mtSNPs play a role in cancer development $[8,25,31,34]$, could both activate an oncogenic pathway which would lead to being a risk factor for cancer occurrence, or activate the apoptotic reaction, which could display a protective effect in the late stages of cancer development. Other determining factors in 
Table 5 Effect of non-haplogroup determining mtSNPs on breast cancer, colorectal cancer and thyroid cancer

\begin{tabular}{|c|c|c|c|c|c|c|c|c|c|c|c|c|}
\hline \multirow[b]{2}{*}{ mtSNPs } & \multicolumn{3}{|c|}{ CCS of breast cancer } & \multirow[b]{2}{*}{$P$ value } & \multicolumn{3}{|c|}{ CCS of colorectal cancer } & \multirow[b]{2}{*}{$P$ value } & \multicolumn{3}{|c|}{ CCS of thyroid cancer } & \multirow[b]{2}{*}{$P$ value } \\
\hline & $\begin{array}{l}\text { Controls } \\
(\mathrm{N}=114)\end{array}$ & $\begin{array}{c}\text { Cases } \\
(\mathrm{N}=104)\end{array}$ & $\begin{array}{l}\text { OR } \\
(95 \% \mathrm{Cl})\end{array}$ & & $\begin{array}{l}\text { Controls } \\
(\mathrm{N}=125)\end{array}$ & $\begin{array}{c}\text { Cases } \\
(\mathrm{N}=108)\end{array}$ & $\begin{array}{l}\text { OR } \\
(95 \% \mathrm{Cl})\end{array}$ & & $\begin{array}{l}\text { Controls } \\
(\mathrm{N}=138)\end{array}$ & $\begin{array}{c}\text { Cases } \\
(\mathrm{N}=100)\end{array}$ & $\begin{array}{l}\text { OR } \\
(95 \% \mathrm{Cl})\end{array}$ & \\
\hline T16140C & 11 & 7 & $0.68(0.25-1.81)$ & 0.434 & 13 & 14 & $1.28(0.58-2.87)$ & 0.542 & 13 & 7 & $0.72(0.28-1.89)$ & 0.507 \\
\hline A16182C & 11 & 18 & $1.96(0.88-4.37)$ & 0.096 & 18 & 11 & $0.67(0.30-1.50)$ & 0.331 & 15 & 13 & $1.23(0.56-2.71)$ & 0.615 \\
\hline A16183C & 29 & 28 & $1.08(0.59-1.98)$ & 0.803 & 36 & 22 & $0.63(0.34-1.16)$ & 0.138 & 32 & 25 & $1.10(0.61-2.01)$ & 0.747 \\
\hline T16189C & 38 & 35 & $1.01(0.58-1.78)$ & 0.960 & 42 & 36 & $0.99(0.57-1.71)$ & 0.966 & 46 & 26 & $0.70(0.40-1.24)$ & 0.224 \\
\hline T16217C & 16 & 11 & $0.72(0.32-1.64)$ & 0.439 & 17 & 9 & $0.58(0.25-1.36)$ & 0.203 & 19 & 9 & $0.62(0.27-1.43)$ & 0.260 \\
\hline C16223T & 69 & 68 & $1.23(0.71-2.14)$ & 0.458 & 73 & 66 & $1.12(0.66-1.89)$ & 0.674 & 83 & 62 & $1.08(0.64-1.83)$ & 0.772 \\
\hline T16298C & 10 & 12 & $1.36(0.56-3.29)$ & 0.498 & 10 & 14 & $1.71(0.73-4.03)$ & 0.214 & 12 & 6 & $0.67(0.24-1.85)$ & 0.438 \\
\hline T16304C & 11 & 13 & $1.33(0.57-3.13)$ & 0.502 & 23 & 14 & $0.66(0.32-1.36)$ & 0.257 & 28 & 13 & $0.59(0.29-1.20)$ & 0.142 \\
\hline T16311C & 20 & 17 & $0.92(0.45-1.87)$ & 0.814 & 23 & 13 & $0.61(0.29-1.27)$ & 0.180 & 19 & 9 & $0.62(0.27-1.43)$ & 0.260 \\
\hline G16319A & 15 & 13 & $0.94(0.43-2.09)$ & 0.885 & 11 & 18 & $2.07(0.93-4.61)$ & 0.070 & 17 & 16 & $1.36(0.65-2.83)$ & 0.417 \\
\hline $\mathrm{T} 146 \mathrm{C}$ & 16 & 17 & $1.20(0.57-2.51)$ & 0.634 & 13 & 17 & $1.61(0.74-3.49)$ & 0.225 & 20 & 10 & $0.66(0.29-1.47)$ & 0.303 \\
\hline С150T & 28 & 33 & $1.43(0.79-2.59)$ & 0.239 & 33 & 25 & $0.84(0.46-1.53)$ & 0.567 & 33 & 22 & $0.90(0.49-1.66)$ & 0.730 \\
\hline T152C & 20 & 23 & $1.34(0.68-2.61)$ & 0.397 & 27 & 26 & $1.15(0.62-2.13)$ & 0.653 & 33 & 31 & $1.43(0.80-2.55)$ & 0.224 \\
\hline 249delA & 20 & 19 & $1.05(0.53-2.10)$ & 0.889 & 25 & 23 & $1.08(0.57-2.04)$ & 0.807 & 31 & 13 & $0.52(0.25-1.05)$ & 0.063 \\
\hline 524delAC & 42 & 27 & $0.60(0.34-1.07)$ & 0.084 & 43 & 33 & $0.84(0.48-1.46)$ & 0.532 & 52 & 42 & $1.20(0.71-2.0)$ & 0.501 \\
\hline
\end{tabular}

$P$ values were estimated by "chi-square test"; $\left(^{*}\right)$ indicated statistical significant $(\mathrm{P}<0.05)$. OR indicates odds ratio; 95\% Cl, 95\% confidence interval.3 
this process include the cellular thresholds required to activate those pathways, which also could be tissuespecific.

Another major finding of our studies is that mtDNA haplogroups D4a and D5 were associated with an increased risk of breast cancer and thyroid cancer, respectively, in the southern Chinese population. In a previous investigation on longevity in a Japanese population, D4a and D5 were found to be enriched in centenarians[25]. It was further hypothesized that the replacement of Ile78Thr in the cytochrome b subunit of respiratory complex III in D4a, and Ile278Val in ND2 and Ile423Val in ND4 of complex I in D5 could play roles in modulating ROS production[25,26]. It is worth noting that aging and cancer could both result from the deregulation of cell homeostasis[49]. The regulation of homeostasis is mostly achieved by the balanced control of cell death and cell proliferation. Thus it is possible that the long lifespan observed to be associated with D4a and D5 could be achieved at the expense of higher cancer incidence. Consistent with this notion, it was reported that D5a and D4a are risk factors of esophageal cancer in the Chaoshan and Taihang Mountain areas of southern China[35]. In fact, most patients and control subjects identified as D5 in our study are indeed D5a, as most of the D5 sub-haplogroup individuals in southern China could be further designated as D5a. In another study, haplogroup D was suggested as a likely risk factor for endometrial cancer in southwestern China[50].

In addition to 10398 variants, the functional implications of the haplopgroup J defining mtSNP C295T in the D-loop region were also examined. It was reported that C295T was associated with an increased binding of TFAM (transcription factor A, mitochondrial), and as a result, cybrids with haplogroup J had a significantly increased mtDNA copy number compared with those carrying haplogroup $\mathrm{H}[51]$. It is possible that the combination of $16362 \mathrm{C}$ and 16129A in the D-loop region observed in our study could have an effect on mtDNA replication and/or transcription as well.

Furthermore, a major finding of our study suggested that mitochondrial macro-haplogroup $\mathrm{M}$ or $\mathrm{mtSNP}$ 10398G could exert different effects under different nuclear background. This is consistent with results of our previous study in which we found that mtDNA mutations, probably mediated by ROS and apoptosis, can play different roles in different stages of cancer development[52]. The potential regulation of tumorigenesis by mtDNA haplogroups or mtSNPs is likely facilitated by nuclear encoded factors, as evidenced by the tissue-specific and population-specific features of mtDNA haplogroups. To test this hypothesis, it would be necessary to extend our investigation to include a greater diversity of populations and cancer types, and more importantly complementary functional assays.

Finally, based on results obtained from this study, an extended investigation including larger cohort and with more cancer types would be warranted to reveal further the interaction between mitochondrial and nuclear genome in cancer cells.

\section{Conclusions}

We found macro-haplogroup $M$ and its sub-haplogroup D5 exhibited an increased risk of breast cancer occurrence but haplogroup $M$ was decreased in the metastatic group. On the other hand, haplogroup D4a was associated with an increased risk of thyroid cancer, while no significant correlation has been detected between any mtDNA haplogroups and colorectal cancer occurrence. Our data indicate that mitochondrial haplogroups could have a tissue-specific, population-specific and stagespecific role in modulating cancer development.

\section{Acknowledgements}

This work is supported by Zhejiang provincial top key discipline of laboratory medicine, Zhejiang provincial program for the cultivation of high level innovative health talents, and National Science Foundation of China (No. 30800620). Yidong Bai is supported by a NIH grant (R01 AG025223).

\section{Author details}

'Zhejiang Provincial Key Laboratory of Medical Genetics, Wenzhou Medical College, Wenzhou 325035, China. ${ }^{2}$ Department of pathology of the First Affiliated Hospital, Wenzhou Medical College, Wenzhou 325000, China.

${ }^{3}$ Department of Cellular and Structural Biology, University of Texas Health Science Center at San Antonio, San Antonio, TX 78229, USA.

\section{Authors' contributions}

HF carried out the sequencing analysis. HF, LS, ZD, JW, JQ and GC collected samples and carried out the pathological analysis. HF, LS, TC and JH carried out the statistical analysis. YB, $J$ and HF conceived the study, participated in the design the experiments and drafted the manuscript. All authors read and approved the final manuscript

\section{Competing interests}

The authors declare that they have no competing interests.

Received: 25 February 2010 Accepted: 12 August 2010 Published: 12 August 2010

\section{References}

1. Wallace DC: Mitochondria as chi. Genetics 2008, 179(2):727-735

2. Warburg O: On the origin of cancer cell. Science 1956, 123:309-314.

3. Lu J, Sharma LK, Bai Y: Implications of mitochondrial DNA mutations and mitochondrial dysfunction in tumorigenesis. Cell Res 2009, 19(7):802-815.

4. Shen $L$, Fang $H$, Chen $T$, He J, Zhang $M$, Wei $X$, Xin $Y$, Jiang $Y$, Ding $Z$, Ji J, et al: Evaluating mitochondrial DNA in cancer occurrence and development. Ann N Y Acad Sci 1201, 26-33.

5. Pedersen PL: Tumor mitochondria and the bioenergetics of cnacer cells. Proc Exp Tumor Res 1978, 22:190-274.

6. Clayton DA, Vinograd J: Circular dimer and catenate forms of mitochondrial DNA in human leukaemic leucocytes. J Pers 1967 35(4):652-657

7. Clayton DA, Vinograd J: Complex mitochondrial DNA in leukemic and normal human myeloid cells. Proc Natl Acad Sci USA 1969 62(4):1077-1084

8. Brandon $M$, Baldi $P$, Wallace DC: Mitochondrial mutations in cancer. Oncogene 2006, 25(34):4647-4662. 
9. Chatterjee A, Mambo E, Sidransky D: Mitochondrial DNA mutations in human cancer. Oncogene 2006, 25(34):4663-4674.

10. Shen L, Wei J, Chen T, He J, Qu J, He X, Jiang L, Qu Y, Fang H, Chen G, et al: Evaluating mitochondrial DNA in patients with breast cancer and benign breast disease. J Cancer Res Clin Oncol.

11. Pakendorf B, Stoneking M: Mitochondrial DNA and human evolution. Annu Rev Genomics Hum Genet 2005, 6:165-183.

12. Watson $\mathrm{E}$, Forster $\mathrm{P}$, Richards $\mathrm{M}$, Bandelt $\mathrm{HJ}$ : Mitochondrial footprints of human expansions in Africa. Am J Hum Genet 1997, 61(3):691-704.

13. Johnson MJ, Wallace DC, Ferris SD, Rattazzi MC, Cavalli-Sforza LL: Radiation of human mitochondria DNA types analyzed by restriction endonuclease cleavage patterns. J Mol Evol 1983, 19(3-4):255-271.

14. Ruiz-Pesini E, Mishmar D, Brandon M, Procaccio V, Wallace DC: Effects of purifying and adaptive selection on regional variation in human mtDNA. Science 2004, 303(5655):223-226.

15. Tanaka M, Takeyasu T, Fuku N, Li-Jun G, Kurata M: Mitochondrial genome single nucleotide polymorphisms and their phenotypes in the Japanese. Ann N Y Acad Sci 2004, 1011:7-20.

16. Wallace DC: A mitochondrial paradigm of metabolic and degenerative diseases, aging, and cancer: a dawn for evolutionary medicine. Annu Rev Genet 2005, 39:359-407.

17. Cai XY, Wang XF, Li SL, Qian J, Qian DG, Chen F, Yang YJ, Yuan ZY, Xu J, Bai $Y$, et al: Association of mitochondrial DNA haplogroups with exceptional longevity in a chinese population. PLOS One 2009, 4(7):e6423.

18. Yao YG, Kong QP, Zhang YP: Mitochondrial DNA 5178A polymorphism and longevity. Hum Genet 2002, 111(4-5):462-463.

19. Fuku N, Park KS, Yamada Y, Nishigaki Y, Cho YM, Matsuo H, Segawa T, Watanabe S, Kato K, Yokoi K, et al: Mitochondrial haplogroup N9a confers resistance against type 2 diabetes in Asians. Am J Hum Genet 2007, 80(3):407-415

20. Tanaka M, Fuku N, Nishigaki Y, Matsuo H, Segawa T, Watanabe S, Kato K, Yokoi K, Ito M, Nozawa Y, et al: Women with mitochondrial haplogroup N9a are protected against metabolic syndrome. Diabetes 2007, 56(2):518-521.

21. Ji Y, Zhang AM, Jia X, Zhang YP, Xiao X, Li S, Guo X, Bandelt HJ, Zhang Q, Yao YG: Mitochondrial DNA haplogroups M7b1'2 and M8a affect clinical expression of leber hereditary optic neuropathy in Chinese families with the m.11778G->a mutation. Am J Hum Genet 2008, 83(6):760-768.

22. Tanaka N, Goto YI, Akanuma J, Kato M, Kinoshita T, Yamashita F, Tanaka M, Asada T: Mitochondrial DNA variants in a Japanese population of patients with Alzheimer's disease. Mitochondrion 2010, 10(1):32-37

23. Hendrickson SL, Hutcheson HB, Ruiz-Pesini E, Poole JC, Lautenberger J, Sezgin E, Kingsley L, Goedert JJ, Vlahov D, Donfield S, et al: Mitochondrial DNA haplogroups influence AIDS progression. AIDS 2008, 22(18):2429-2439.

24. Hendrickson SL, Kingsley LA, Ruiz-Pesini E, Poole JC, Jacobson LP, Palella FJ, Bream JH, Wallace DC, O'Brien SJ: Mitochondrial DNA haplogroups influence lipoatrophy after highly active antiretroviral therapy. I Acquir Immune Defic Syndr 2009, 51(2):111-116.

25. Alexe G, Fuku N, Bilal E, Ueno H, Nishigaki Y, Fujita Y, Ito M, Arai $Y$, Hirose $N$, Bhanot $G$, et al: Enrichment of longevity phenotype in mtDNA haplogroups D4b2b, D4a, and D5 in the Japanese population. Hum Genet 2007, 121(3-4):347-356.

26. Bilal E, Rabadan R, Alexe G, Fuku N, Ueno H, Nishigaki Y, Fujita Y, Ito M, Arai $Y$, Hirose $N$, et al: Mitochondrial DNA haplogroup D4a is a marker for extreme longevity in Japan. PLoS One 2008, 3(6):e2421.

27. Kong QP, Bandelt HJ, Sun C, Yao YG, Salas A, Achilli A, Wang CY, Zhong L, Zhu CL, Wu SF, et al: Updating the East Asian mtDNA phylogeny: a prerequisite for the identification of pathogenic mutations. Hum Mol Genet 2006, 15(13):2076-2086.

28. Yao YG, Kong QP, Bandelt HJ, Kivisild T, Zhang YP: Phylogeographic differentiation of mitochondrial DNA in Han Chinese. Am J Hum Genet 2002, 70(3):635-651.

29. Niemi AK, Moilanen JS, Tanaka M, Hervonen A, Hurme M, Lehtimaki T, Arai $Y$, Hirose N, Majamaa K: A combination of three common inherited mitochondrial DNA polymorphisms promotes longevity in Finnish and Japanese subjects. Eur J Hum Genet 2005, 13(2):166-170.

30. van der Walt JM, Nicodemus KK, Martin ER, Scott WK, Nance MA, Watts RL, Hubble JP, Haines JL, Koller WC, Lyons K, et al: Mitochondrial polymorphisms significantly reduce the risk of Parkinson disease. Am J Hum Genet 2003, 72(4):804-811
31. Canter JA, Kallianpur AR, Parl FF, Millikan RC: Mitochondrial DNA G10398A polymorphism and invasive breast cancer in African-American women. Cancer Res 2005, 65(17):8028-8033.

32. Mims MP, Hayes TG, Zheng $S$, Leal SM, Frolov A, Ittmann MM, Wheeler TM, Prchal JT: Mitochondrial DNA G10398A polymorphism and invasive breast cancer in African-American women. Cancer Res 2006, 66(3):1880, author reply 1880-1881..

33. Darvishi K, Sharma S, Bhat AK, Rai E, Bamezai RN: Mitochondrial DNA G10398A polymorphism imparts maternal Haplogroup N a risk for breast and esophageal cancer. Cancer Lett 2007, 249(2):249-255.

34. Bai RK, Leal SM, Covarrubias D, Liu A, Wong LJ: Mitochondrial genetic background modifies breast cancer risk. Cancer Res 2007, 67(10):4687-4694.

35. Li XY, Su M, Huang HH, Li H, Tian DP, Gao YX: mtDNA evidence: genetic background associated with related populations at high risk for esophageal cancer between Chaoshan and Taihang Mountain areas in China. Genomics 2007, 90(4):474-481.

36. Deng JH, Li Y, Park JS, Wu J, Hu P, Lechleiter J, Bai Y: Nuclear suppression of mitochondrial defects in cells without the ND6 subunit. Mol Cell Biol 2006, 26(3):1077-1086.

37. Rieder MJ, Taylor SL, Tobe VO, Nickerson DA: Automating the identification of DNA variations using quality-based fluorescence resequencing: analysis of the human mitochondrial genome. Nucleic Acids Res 1998, 26(4):967-973.

38. Andrews RM, Kubacka I, Chinnery PF, Lightowlers RN, Turnbull DM, Howell N: Reanalysis and revision of the Cambridge reference sequence for human mitochondrial DNA. Nat Genet 1999, 23(2):147.

39. Kivisild T, Tolk HV, Parik J, Wang Y, Papiha SS, Bandelt HJ, Villems R: The emerging limbs and twigs of the East Asian mtDNA tree. Mol Biol Evol 2002, 19(10):1737-1751.

40. Torroni A, Achilli A, Macaulay V, Richards M, Bandelt HJ: Harvesting the fruit of the human mtDNA tree. Trends Genet 2006, 22(6):339-345.

41. Wenqiu Zheng ZZ: An Analysis Of Cancer Incidencee In 2005 In Lucheng Discricr, Wenzhou City. Journal Of Chinese Cancer 2007, 16(5):306-308.

42. Kazuno AA, Munakata K, Nagai T, Shimozono S, Tanaka M, Yoneda M, Kato N, Miyawaki A, Kato T: Identification of mitochondrial DNA polymorphisms that alter mitochondrial matrix $\mathrm{pH}$ and intracellular calcium dynamics. PLoS Genet 2006, 2(8):e128.

43. Shoffner JM, Brown MD, Torroni A, Lott MT, Cabell MF, Mirra SS, Beal MF, Yang CC, Gearing M, Salvo R, et al: Mitochondrial DNA variants observed in Alzheimer disease and Parkinson disease patients. Genomics 1993, 17(1):171-184.

44. Mancuso M, Conforti FL, Rocchi A, Tessitore A, Muglia M, Tedeschi G, Panza D, Monsurro M, Sola P, Mandrioli J, et al: Could mitochondrial haplogroups play a role in sporadic amyotrophic lateral sclerosis? Neurosci Lett 2004, 371(2-3):158-162.

45. Czarnecka AM, Krawczyk T, Zdrozny M, Lubinski J, Arnold RS, Kukwa W, Scinska A, Golik P, Bartnik E, Petros JA: Mitochondrial NADHdehydrogenase subunit 3 (ND3) polymorphism (A10398G) and sporadic breast cancer in Poland. Breast Cancer Res Treat 2010, 121(2):511-518.

46. Setiawan WW, Chu LH, John EM, Ding YC, Ingles SA, Bernstein L, Press MF, Ursin G, Haiman CA, Neuhausen SL: Mitochondrial DNA G10398A variant is not associated with breast cancer in African-American women. Cancer Genet Cytogenet 2008, 181(1):16-19.

47. Mosquera-Miguel A, Alvarez-Iglesias V, Carracedo A, Salas A, Vega A, Milne $\mathrm{R}$, de Leon $A C$, Benitez J: Is mitochondrial DNA variation associated with sporadic breast cancer risk? Cancer Res 2008, 68(2):623-625, author reply 624 .

48. Datta S, Majumder M, Biswas NK, Sikdar N, Roy B: Increased risk of oral cancer in relation to common Indian mitochondrial polymorphisms and Autosomal GSTP1 locus. Cancer 2007, 110(9):1991-1999.

49. Zhang JH, Zhang Y, Herman B: Caspases, apoptosis and aging. Ageing Res Rev 2003, 2(4):357-366.

50. Xu L, Hu Y, Chen B, Tang W, Han X, Yu H, Xiao C: Mitochondrial polymorphisms as risk factors for endometrial cancer in southwest China. Int J Gynecol Cancer 2006, 16(4):1661-1667.

51. Suissa S, Wang Z, Poole J, Wittkopp S, Feder J, Shutt TE, Wallace DC, Shadel GS, Mishmar D: Ancient mtDNA genetic variants modulate mtDNA transcription and replication. PLoS Genet 2009, 5(5):e1000474.

52. Park JS, Sharma LK, Li H, Xiang R, Holstein D, Wu J, Lechleiter J, Naylor SL, Deng JJ, Lu J, et al: A heteroplasmic, not homoplasmic, mitochondrial 
DNA mutation promotes tumorigenesis via alteration in reactive oxygen species generation and apoptosis. Hum Mol Genet 2009, 18(9):1578-1589.

53. Hertzberg M, Mickleson KN, Serjeantson SW, Prior JF, Trent RJ: An Asianspecific 9-bp deletion of mitochondrial DNA is frequently found in Polynesians. Am J Hum Genet 1989, 44(4):504-510.

Pre-publication history

The pre-publication history for this paper can be accessed here: http://www.biomedcentral.com/1471-2407/10/421/prepub

doi:10.1186/1471-2407-10-421

Cite this article as: Fang et al: Cancer type-specific modulation of mitochondrial haplogroups in breast, colorectal and thyroid cancer. BMC Cancer 2010 10:421.

\section{Submit your next manuscript to BioMed Central} and take full advantage of:

- Convenient online submission

- Thorough peer review

- No space constraints or color figure charges

- Immediate publication on acceptance

- Inclusion in PubMed, CAS, Scopus and Google Scholar

- Research which is freely available for redistribution

Submit your manuscript at www.biomedcentral.com/submit 